\title{
Sleep pattern, obesity and healthcare expenditures in Brazilian adults
}

\author{
Padrões do sono, obesidade e despesas em saúde com brasileiros \\ adultos
}

Eduardo Pereira da Silva (http://orcid.org/0000-0003-2441-1990) ${ }^{1}$

Ana Paula Rodrigues Rocha (https://orcid.org/0000-0003-1359-5325) ${ }^{2}$

Monique Yndawe Castanho Araujo (http://orcid.org/0000-0001-8131-8202) ${ }^{1}$

Bruna Camilo Turi (https://orcid.org/0000-0002-2803-1058) ${ }^{3}$

Rômulo Araújo Fernandes (https://orcid.org/0000-0003-1576-8090) ${ }^{1}$

Jamile Sanches Codogno (http://orcid.org/0000-0003-4273-9375) ${ }^{1}$
${ }^{1}$ Faculdade de Ciência e Tecnologia, Universidade Estadual Paulista Júlio de Mesquita Filho. R. Roberto Simonsen 305, Jardim das Rosas. 19060-900 Presidente Prudente SP Brasil. eduardoplug@gmail.com ${ }^{2}$ Universidade Federal de São Carlos. São Carlos SP Brasil.

${ }^{3}$ Physical Education and Exercise Science Department, Lander University. Greenwood SC EUA.

\begin{abstract}
The aim of this study was to analyze the relationship between sleep pattern and healthcare expenditures in adults, as well as to identify whether physical activity, biochemical markers and obesity affect this relationship. The sample was composed of 168 adults aged $\geq 50$ years attended by two Basic Healthcare Units in Presidente Prudente, SP, Brazil. Health expenditure, sleep pattern, anthropometry, adiposity index, physical activity, metabolic and cardiovascular variables were assessed. Statistical analyses were performed using Kruskal-Wallis, Mann-Whitney and Spearman tests. Sleep disorders were positively correlated to higher costs with medicines and negatively correlated to costs with laboratory tests, even after adjusts by confounders. In addition, healthcare costs were also correlated to physical activity score, blood pressure, obesity and metabolic variables. Severe sleep disorders and high percentage of body fat were associated with increased use of medications. Sleep pattern is correlated to primary care healthcare costs, obesity and physical activity level.
\end{abstract}

Key words Healthcare costs, Sleep wake disorders, Body fat distribution
Resumo O objetivo deste estudo foi analisar a relação entre padrão de sono e despesas de saúde em adultos, bem como identificar se atividade física, marcadores bioquímicos e obesidade afetam esse relacionamento. A amostra foi composta por 168 adultos com idade $\geq 50$ anos atendidos por duas unidades básicas de saúde em Presidente Prudente, SP, Brasil. Foram avaliadas as despesas de saúde, padrões do sono, antropometria, atividade física, variáveis metabólicas e cardiovasculares. Foram utilizados Kruskal-Wallis, Mann-Whitney e Spearman. Os distúrbios do sono foram correlacionados positivamente com os custos mais elevados com medicamentos e negativamente com os custos com testes laboratoriais, mesmo após ajuste por fatores de confusão. Além disso, os custos de saúde também foram correlacionados ao escore de atividade física, pressão arterial, obesidade e variáveis metabólicas. Distúrbios graves do sono e alta porcentagem de gordura corporal foram associados ao aumento do uso de medicamentos. $O$ padrão de sono está correlacionado com os custos de cuidados de saúde primários, obesidade e atividade fisica.

Palavras-chave Custos de cuidados de saúde, Transtornos do sono-vigília, Distribuição da gordura corporal 


\section{Introduction}

Obesity is a major public health problem that has attracted considerable attention worldwide ${ }^{1}$. The prevalence of overweight and obesity in Brazil was $52.5 \%$ and $17.9 \%$ in 2014, respectively ${ }^{2}$, and this numbers continue to increase year after year. Obesity is associated with modification in several comorbidities, including sleep-related disorders, which also affect cardiovascular and metabolic markers ${ }^{3,4}$. Zanuto et al. ${ }^{5}$ found high prevalence of sleep disorders in a sample of Brazilian adults (46.6\%), which was associated with overweight and obesity. Hanlon et al. ${ }^{6}$ identified that the ratio ghrelin peak / leptin peak increased in patients following restricted sleep, suggesting a change in neuroendocrine signaling, which could promote hunger and less satiety, and as consequence, it would be related to obesity and overweight.

On the other hand, physical activity is recognized to be an important behavior related to health outcomes, mainly because it promotes beneficial changes in body composition ${ }^{6}$. In a recent study, Chen et al. ${ }^{7}$ showed that moderate to intense physical activity performed during eight to 12 weeks caused significant reductions in fat percentage $(-3.4 \%)$, decreased fat mass $(-3.1 \mathrm{Kg})$ and increased lean mass $(2 \mathrm{Kg})$, with effects lasting for four weeks, including in older adults with BMI above $28.1 \mathrm{Kg} / \mathrm{m}^{2}$.

Additionally, besides the impact on health, sleep pattern can also affect healthcare costs directly and indirectly ${ }^{8}$. Medical costs associated with sleep disorders account for US\$146 million per year in the United States and more than US\$ 1.5 billion per year in Australia ${ }^{8-10}$. According to Kyle et al. ${ }^{11}$, individuals with sleep disorders tend to report excessive sleepiness, fatigue, mood swings, and reduced pain tolerance, which increase the use of medical care and medicine ${ }^{12}$. On the other hand, physical activity is inversely related to healthcare costs ${ }^{13,14}$ According to a Brazilian research, $50 \%$ reduction of physical inactivity could save more than 1 billion dollars related to medicines due to the positive effects of physical activity in chronic diseases ${ }^{15,16}$. Therefore, the objective of the present study was to analyze the relationship between sleep pattern and healthcare expenditures in adults, as well as to identify whether physical activity, biochemical markers and obesity affect this relationship.

\section{Methods}

\section{Sample}

This project was a cross-sectional study conducted in March 2016 in the city of Presidente Prudente. Prior to implementation the study was approved by the Ethics Committee Group from the Faculty of Science and Technology, Sao Paulo State University, Presidente Prudente campus and all subjects were asked to sign a consent form.

Sample size estimation was based in standardized measures of linear relationship $(r)$, in which the minimum sample size of 161 participants granted a statistical power of $80 \%$ to detect significant relationships of $\geq 0.21$. After the fieldwork, the final sample size was composed of 168 participants.

The sample consisted of adults aged $\geq 50$ years of both sexes attended by two Basic Healthcare Units (BHU) located in different regions in the city of Presidente Prudente, SP. BHU are small medical facilities that offer a large variety of primary care services in the Brazilian National Health System (NHS), constituting the most distal level of the NHS. These two BHU were indicated by the Municipal Department of Health according to the location and number of patients attended (the two largest BHU were selected). As inclusion criteria were defined: a) age $\geq 50$ years; b) register for at least one year at the BHU; c) have active registration of healthcare service (have performed at least one medical visit in the past six months).

\section{Healthcare expenditures}

Annual healthcare expenditure of each participant was estimated including all items registered in the medical records in the last 12 months prior to the interview conducted in this study. The healthcare expenditures were categorized into: medical consultations (all medical specialties), exams (clinical and laboratory tests), medicines (released to the patients according to medical prescription) and overall. After that, all expenditures were computed in the Brazilian currency (Real) and converted to US dollar using the average value of the dollar against the Brazilian currency in the 12 months of 2016 (US\$ 1.00 equals to $\mathrm{R} \$ 3.10)$. 


\section{Sleep pattern}

The Mini-Sleep Questionnaire is a self-report of current sleep quality, which is measured by ten questions about the frequency of sleep difficulties. Answer options range from 1 (never) to 7 (always), with higher scores meaning more sleep difficulties. The total score is classified into good sleep (10-24), mild sleep difficulties (25-27), moderate difficulties (28-30), and severe difficulties (>30). The questionnaire was validated for the Brazilian population by Falavigna et al. ${ }^{17}$.

\section{Anthropometry and adiposity index}

Body mass index (BMI) was calculated using measurements of weight and height ${ }^{18}$ and obtained by dividing weight by squared height $\left(\mathrm{kg} / \mathrm{m}^{2}\right)$. Obesity was defined as BMI $\geq 30 \mathrm{~kg} / \mathrm{m}^{2}$ 19. Abdominal obesity was assessed using waist circumference (WC) measurements, which was collected following the protocol proposed by Lohman et al. ${ }^{18}$. Body fatness (\%) was estimated by bioelectrical impedance analysis (InBody brand model 230 model) according to manufacturer's instructions.

\section{Metabolic and cardiovascular variables}

Blood pressure was measured in a seated position at rest and followed the protocol proposed by the VII Brazilian Guidelines for Hyperten$\operatorname{sion}^{20}$. Fasting glucose, triglycerides, total cholesterol, high, low and very low-density lipoproteins (HDL-C, LDL-C and VLDL-C, respectively) were evaluated in the morning after 10 to 12 hours of fasting in a private laboratory (all metabolic variables were expressed in $\mathrm{mg} / \mathrm{dL}$ ).

\section{Domains of physical activity}

In the present study, the Baecke et al. ${ }^{21}$ questionnaire was used to assess self-reported physical activity. The questionnaire was translated and validated into a Brazilian Portuguese version ${ }^{22}$. The questionnaire presents good reproducibility among Brazilian adults ${ }^{22,23}$ and satisfactory validity against doubly labeled water method in elderly subjects ${ }^{24}$. The instrument comprises 16 questions scored on 5-point Likert scales (ranging from never to always/very often) addressing three domains of physical activity: occupational, exercise / sports participation and leisure-time / locomotion physical activity. The sum of these three domains denotes the overall physical activity level. Physical activity scores were calculated for each domain and overall according to instructions in the questionnaire.

\section{Statistical analysis}

Descriptive statistics were composed of mean, median, 95\% confidence interval $(95 \% \mathrm{CI})$ and interquartile range (IR). Due to the non-parametric distribution of data, comparisons among groups were performed using Kruskal-Wallis test and Mann-Whitney test. The relationship between healthcare costs and independent variables was assessed by Spearman correlation after logarithmic transformation of the non-parametric variables (expressed as standardized coefficients $[r]$ and adjusted by all confounders). Statistical analyses were performed by the software BioEstat (release 5.0) and statistical significance (p-value) was set at 0.05 .

\section{Results}

The sample was composed of 168 adults of both sexes (52 men [31\%] and 116 women [69\%]), and the average age was $63.8 \pm 8.6$ years. Descriptive information of the participants is presented in Table 1.

The prevalence of sleep disturbances was 64.9\% ( $\mathrm{n}=109$; categories light, moderate and severe combined). People with the worse quality of sleep presented higher BMI ( $\mathrm{p}$-value $=0.003$ ), body fatness $(p$-value $=0.002)$, total cholesterol $(\mathrm{p}$-value $=0.015)$ and healthcare costs related to medicines $(\mathrm{p}$-value $=0.010)($ Table 2$)$.

The relationship between healthcare costs and sleep pattern is presented in Table 3. The occurrence of sleep disorders was positively correlated with higher healthcare costs with medicine, and negatively correlated to healthcare costs with to exams. Healthcare costs were also correlated to behavioral, cardiovascular and metabolic variables.

Moreover, the relationship between healthcare costs and sleep disorders was assessed using a multivariate model, and the coefficients were presented as standardized units (Table 4). The relationship between sleep pattern and healthcare costs with exams $(r=-0.166[-0.313$ to -0.012$])$ and medicines ( $r=0.213$ [0.052 to 0.363$]$ ) remained significant even after adjustment by confounders. 
Table 1. Descriptive characteristics of the sample ( $n=168$; Presidente Prudente, SP, Brazil, 2016).

\begin{tabular}{|c|c|c|}
\hline & \multicolumn{2}{|c|}{ Descriptive statistics $(n=168)$} \\
\hline & Mean $(95 \% \mathrm{CI})$ & Median (IR) \\
\hline MSQ score & $30.7(28.8 ; 32.5)$ & $30(17)$ \\
\hline \multicolumn{3}{|l|}{ Physical activity (score) } \\
\hline Occupational & $2.2(2.1 ; 2.4)$ & $2.6(1.1)$ \\
\hline Exercise / Sports & $1.9(1.8 ; 2.1)$ & $1.7(1.2)$ \\
\hline Leisure-time / locomotion & $2.1(2.1 ; 2.2)$ & $2.2(0.8)$ \\
\hline Overall & $6.4(6.1 ; 6.6)$ & $6.3(1.9)$ \\
\hline \multicolumn{3}{|l|}{ Blood pressure (mmHg) } \\
\hline Systolic blood pressure & $129.8(126.7 ; 132.8)$ & $128(23)$ \\
\hline Diastolic blood pressure & $76.1(74.4 ; 77.9)$ & $75(14)$ \\
\hline \multicolumn{3}{|l|}{ Anthropometry / adiposity } \\
\hline Weight (kg) & $72.1(69.6 ; 74.5)$ & $72.6(19.6)$ \\
\hline Height $(\mathrm{cm})$ & $157.2(155.9 ; 158.6)$ & $156.5(11.5)$ \\
\hline BMI $\left(\mathrm{kg} / \mathrm{m}^{2}\right)$ & $29.1(28.2 ; 30.1)$ & $28.18(6.4)$ \\
\hline $\mathrm{WC}(\mathrm{cm})$ & $95.3(93.1 ; 97.5)$ & $95.5(15.5)$ \\
\hline $\mathrm{BF}(\%)$ & $38.5(37.2 ; 39.8)$ & $38.2(12)$ \\
\hline \multicolumn{3}{|l|}{ Metabolic variables (mg/dL) } \\
\hline Total cholesterol & $198.5(193.1 ; 204.1)$ & $198.50(45.4)$ \\
\hline HDL-C & $45.2(43.6 ; 46.8)$ & $43.8(12.1)$ \\
\hline VLDL-C & $30.5(28.1 ; 32.8)$ & $27.2(17.6)$ \\
\hline LDL-C & $122.8(117.9 ; 127.6)$ & $121(38.5)$ \\
\hline Triglycerides & $151.2(139.6 ; 162.9)$ & $131.4(88.1)$ \\
\hline Fasting glucose & $106.2(98.6 ; 113.8)$ & $91.40(29.3)$ \\
\hline \multicolumn{3}{|l|}{ Health care costs (US\$) } \\
\hline Consultations & $16.62(15.7 ; 18.1)$ & $17.00(11.3)$ \\
\hline Exams & $8.03(5.8 ; 10.1)$ & $0.00(17.8)$ \\
\hline Medicines & $30.01(24.1 ; 35.8)$ & $17.8(29.1)$ \\
\hline Overall & $54.6(48.1 ; 61.3)$ & $44.71(41.4)$ \\
\hline
\end{tabular}

Notes: $95 \% \mathrm{CI}=95 \%$ confidence interval; $\mathrm{IR}=$ interquartile range; $\mathrm{MSQ}=$ mini-sleep questionnaire; $\mathrm{BMI}=$ body mass index; $\mathrm{WC}=$ waist circumference; $\mathrm{BF}=$ body fatness; HDL-C = high-density lipoprotein cholesterol; LDL-C $=$ low-density lipoprotein cholesterol; VLDL-C = very low-density lipoprotein cholesterol.

\section{Discussion}

This cross-sectional study involving patients of the Brazilian National Healthcare System found a high percentage of sleep disorders in this population and identified an important relationship between sleep pattern, behavioral variables and high healthcare expenditures.

Regarding the significant relationship between sleep pattern and physical activity level in leisure-time / locomotion domain, Perrier ${ }^{25}$ point out that physical activity may influence the release of serotonin, a fundamental hormone that regulates sleep/wake cycle, and the amount and intensity of physical activity performed have been linked to better sleep quality ${ }^{25}$. In terms of promotion of healthy habits in the Brazilian Na- tional Health System, the most relevant aspect of our findings is that habitual physical activity measured in free-living conditions was associated with sleep quality ${ }^{5}$, instead of physical exercise protocols performed at laboratorial environments.

On the other hand, when considering the different domains of physical activity, a positive relationship was found between occupational physical activity and healthcare expenditures with medical appointments. The literature has showed that higher levels of physical activity (mainly leisure-time) results in lower healthcare expenditures ${ }^{16,26}$, but data with other domains are still conflicting. In fact, adults who accumulate 30 minutes or more in low to moderate-intensity physical activity are more likely to use preventive 
Table 2. Variables stratified according to sleep pattern ( $\mathrm{n}=168$; Presidente Prudente, SP, Brazil, 2016).

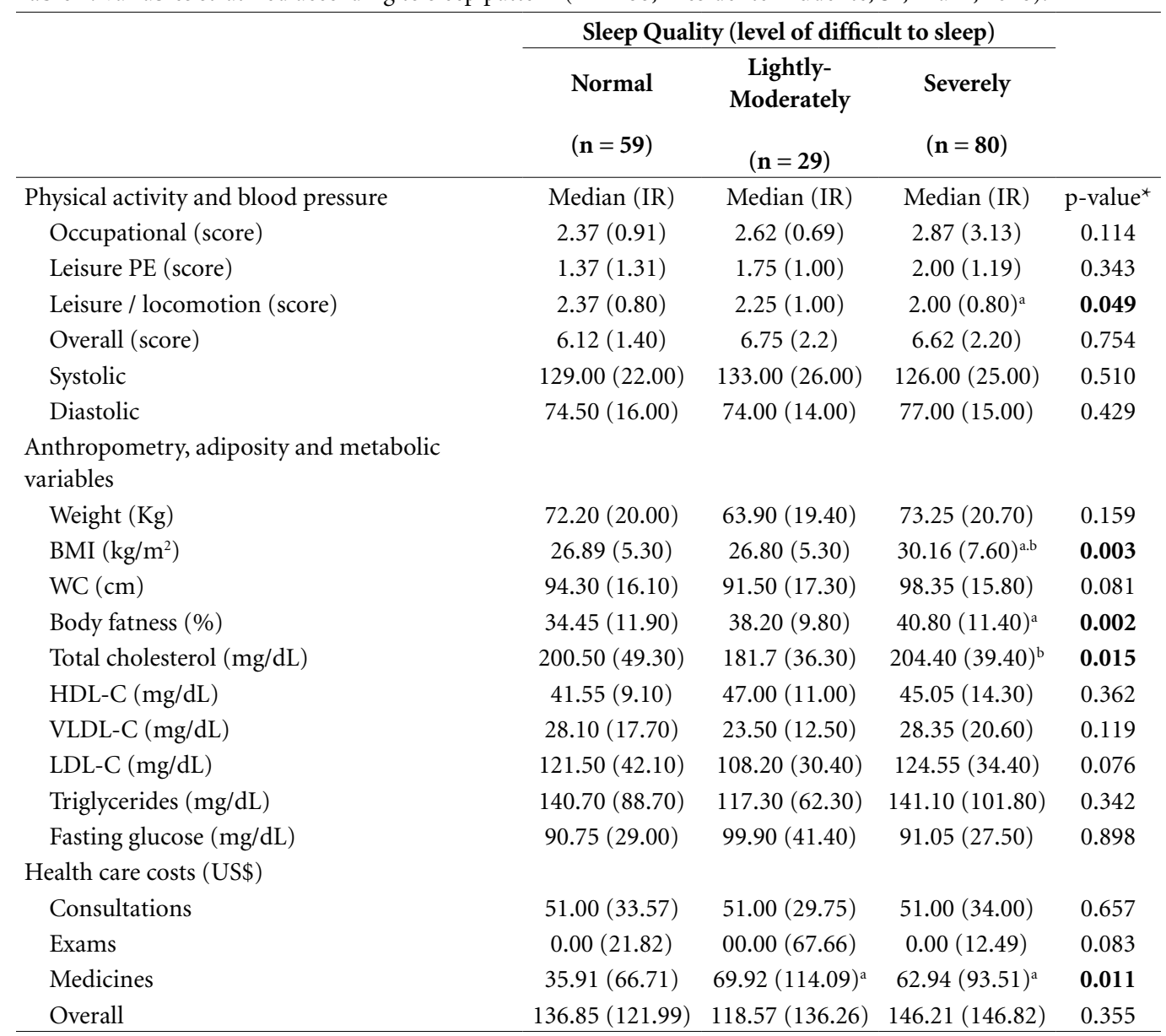

Notes: IR = interquartile range; BMI = body mass index; WC = waist circumference; $\mathrm{BF}=$ body fatness; HDL-C = high-density lipoprotein; LDL-C = low-density lipoprotein; VLDL-C = very low-density lipoprotein; ${ }^{*}=$ Kruskal-Wallis test; a = denotes difference with normal; $\mathrm{b}=$ difference with lightly-moderately.

services offered by the healthcare system ${ }^{27}$, which corroborates and could help to understand our findings. Moreover, some labor activities can require high physical demand, without targeting health improvement (no supervision/orientation), which can lead to an increase of the risk of injuries and negative economic outcomes, such as absenteeism and productivity loss.

Another important result was the positive relationship between adiposity and sleep disorders, which agrees with findings from other studies $^{28-30}$. Over the last decades, the prevalence of overweight and obesity increased in adults around the world, while the population has reduced sleeping time and increased time spent in sedentary behaviors ${ }^{31}$. A possible explanation for this relationship would be bad food choices observed in people with poor sleep quality, because people with more time awake are exposed to a higher consumption of food and snacks during the night ${ }^{6}$, and sedentary behavior is linked to consumption of unhealthy foods ${ }^{31}$. Similarly, harmful modifications in the release of important hormones related to metabolism are also linked with sleep quality ${ }^{32}$. The relationship between adiposity and quality of sleep can also be used to justify the changes in the lipid and glycemic profile observed among patients with poor sleep quality ${ }^{33,34}$.

Concerning the relationship between healthcare expenditures and sleep pattern, studies have shown that adults with sleep disorder usually present higher healthcare expenditures ${ }^{13,14}$. People with insomnia spent $26 \%$ more with medical services during a year when compared to people without the disorder ${ }^{35}$. In Canada, Daley et al. ${ }^{10}$ estimated that the annual direct costs related to sleep disorders was 509.9 million dollars in 2009. 
Table 3. Relationship between health care costs and independent variables in patients attended at primary care of the Brazilian National Health System ( $n=168$; Presidente Prudente, SP, Brazil, 2016).

\begin{tabular}{|c|c|c|c|c|}
\hline & \multicolumn{4}{|c|}{ Health care costs (US\$) } \\
\hline & Consultations & Exams & Medicines & Overall \\
\hline MSQ score & 0.088 & $-0.152^{\star}$ & $0.245^{\star}$ & 0.142 \\
\hline \multicolumn{5}{|l|}{ Physical Activity (score) } \\
\hline Occupational & $0.162^{*}$ & 0.043 & 0.112 & 0.128 \\
\hline Leisure physical exercise & 0.008 & -0.045 & 0.078 & 0.009 \\
\hline Leisure and locomotion & 0.025 & 0.085 & -0.118 & -0.075 \\
\hline Overall & 0.144 & 0.088 & 0.078 & 0.096 \\
\hline \multicolumn{5}{|l|}{ Blood pressure (mmHg) } \\
\hline Systolic & -0.060 & $-0.164^{\star}$ & 0.123 & -0.012 \\
\hline Diastolic & -0.046 & -0.096 & 0.034 & -0.049 \\
\hline \multicolumn{5}{|l|}{ Anthropometry / adiposity } \\
\hline Weight (kg) & -0.009 & -0.023 & 0.034 & 0.055 \\
\hline BMI $\left(\mathrm{kg} / \mathrm{m}^{2}\right)$ & 0.076 & 0.023 & 0.147 & 0.182 \\
\hline $\mathrm{WC}(\mathrm{cm})$ & -0.004 & -0.073 & 0.083 & 0.050 \\
\hline $\mathrm{BF}(\%)$ & 0.104 & -0.052 & 0.126 & 0.145 \\
\hline \multicolumn{5}{|l|}{ Metabolic (mg/dL) } \\
\hline Total cholesterol & 0.085 & -0.075 & -0.035 & -0.083 \\
\hline HDL-C & 0.036 & -0.024 & -0.126 & -0.088 \\
\hline VLDL-C & 0.112 & 0.076 & $0.273^{*}$ & $0.252^{\star}$ \\
\hline LDL-C & 0.046 & -0.111 & -0.132 & $-0.175^{\star}$ \\
\hline Triglycerides & 0.119 & 0.092 & $0.264^{*}$ & $0.239^{*}$ \\
\hline Fasting glucose & -0.022 & 0.075 & $0.181^{\star}$ & $0.184^{*}$ \\
\hline
\end{tabular}

The pathways by which poor sleep quality increases healthcare costs are not entirely clear, but could be supported by its linkage with obesity and depressive symptoms. The economic burden associated with sleep disorders has been pointed out as a public health problem in developed countries $^{10}$ and the findings of this study indicate that the same pattern seems to be observed in developing countries.

Cross-sectional design constitutes a limitation of this study, because causality statements are not possible. A significant limitation of the study is the use of the questionnaire to evaluate sleep pattern, although other variables could be included as sleep timing, circadian interruption and accumulation of sleep loss and fatigue. About the questionnaire used in this study, the mini-sleep questionnaire has been validated in a younger group, denoting caution in its use in older people.
Moreover, due to the non-probability sampling technique (convenience sampling) only two BHU were used in this survey and thus caution is required to any inference of these findings. Another limitation of this study was the non-exclusion of people using sleep medication. The non-exclusion was necessary because economic analyzes were the main outcome of this study, and medication have a great burden on this outcome.

In summary, it was possible to identify that poor sleep quality is positively related to healthcare costs and adiposity, and negatively related to some domains of physical activity. The relationships of low magnitude observed in this study denote that other variables not accounted in these models affect the phenomenon. Thus, future studies should investigate a wide prospectus of variables potentially related to healthcare costs and sleep in Brazilian adults. 


\section{Collaborations}

EP Silva, APR Rocha, MYC Araujo, BC Turi, RA Fernandes and JS Codogno participated in all stages of article elaboration, from study design, data collection, analysis and interpretation, until the final writing and consequent approval of the final version to be published.

\section{Acknowledgments}

The Brazilian Federal Agency for Support and Evaluation of Graduate Education (CAPES), São Paulo Research Foundation and National Counsel of Technological and Scientific Development.

\section{References}

1. Lombardo C. Sleep and Obesity: An Introduction. Eat Weight Disord 2016; 21(1):1-4.

2. Brasil. Ministério da Saúde (MS). Vigitel Brasil 2014: vigilância de fatores de risco e proteção para doenças crônicas por inquérito telefônico. Brasília: MS; 2015.

3. Passali D, Corallo G, Petti A, Longini M, Passali FM, Buonocore G, Bellussi LM. A comparative study on oxidative stress role in nasal breathing impairment and obstructive sleep apnoea syndrome. Acta Otorhinolaryngol Ital 2016; 36(6):490-495.

4. Basnet S, Merikanto I, Lahti T, Männistö S, Laatikainen T, Vartiainen E, Partonen T. Associations of common chronic non-communicable diseases and medical conditions with sleep-related problems in a population-based health examination study. Sleep Sci 2016; 9(3):249-254.

5. Zanuto EAC, Christofaro DGD, Fernandes RA. Sleep quality and its associations with leisure-time exercise and excess weight among civil servants. Braz J Kinathrop Hum Perform 2013; 16(1):27-35.

6. Hanlon EC, Tasali E, Leproult R, Stuhr KL, Doncheck E, de Wit H, Hillard CJ, Van Cauter E. Sleep Restriction Enhances the Daily Rhythm of Circulating Levels of Endocannabinoid 2-Arachidonoylglycerol. Sleep 2016; 39(3):653-664

7. Chen HT, Chung YC, Chen YJ, Ho SY, Wu HJ. Effects of Different Types of Exercise on Body Composition, Muscle Strength, and IGF-1 in the Elderly with Sarcopenic Obesity. J Am Geriatr Soc 2017; 65(4):827-832.

8. Sampasa-Kanyinga H, Chaput JP. Associations among self-perceived work and life stress, trouble sleeping, physical activity, and body weight among Canadian adults. Prev Med 2016; 96:16-20.

9. Garbarino S, Sannita WG. Poor sleeping has underrepresented medical, healthcare, and social costs? Eur J Intern Med 2017; 38:e15-e16.

10. Daley M, Morin CM, LeBlanc M, Grégoire JP, Savard J. The economic burden of insomnia: direct and indirect costs for individuals with insomnia syndrome, insomnia symptoms, and good sleepers. Sleep 2009; 32(1):55-64.

11. Kyle SD, Morgan K, Espie CA. Insomnia and health-related quality of life. Sleep Med Rev 2010; 14(1):69-82.

12. Garbarino S, Lanteri P, Durando P, Magnavita N, Sannita W. Co-Morbidity, Mortality, Quality of Life and the Healthcare/Welfare/Social Costs of Disordered Sleep: A Rapid Review. Int J Environ Res Public Health 2016; 13(8):831.

13. Kaufmann CN, Canham SL, Mojtabai R, Gum AM, Dautovich ND, Kohn R, Spira AP. Insomnia and health services utilization in middle-aged and older adults: results from the Health and Retirement Study. J Gerontol A Biol Sci Med Sci 2013; 68(12):1512-1517.

14. Bramoweth AD, Taylor DJ. Chronic Insomnia and Healthcare Utilization in Young Adults. Behav Sleep Med 2012; 10(2):106-121.

15. Bielemann RM, Knuth AG, Hallal PC. Atividade física e redução de custos por doenças crônicas ao sistema único de saúde. Rev Bras Ativ Fís Saúde 2012; 15(1):914. 
16. Bueno DR, Marucci MF, Codogno JS, Roediger MA. The costs of physical inactivity in the world: a general review. Cien Saude Colet 2016; 21(4):1001-1010.

17. Falavigna A, Souza Bezerra ML, Teles AR, Kleber FD, Velho MC, Silva RC, Mazzochin T, Santin JT, Mosena G, Braga GL, Petry FL, Lessa Medina MF. Consistency and reliability of the Brazilian Portuguese version of the Mini-Sleep Questionnaire in undergraduate students. Sleep Breath 2011; 15(3):351-355.

18. Lohman TG, Roche AF, Martorell R. Anthropometric Standardization Reference Manual. Champaign: $\mathrm{Hu}-$ man Kinetics Books; 1988.

19. World Health Organization (WHO). The World Health Report 1998 - Life in the 21st Century: a vision for all. Geneva: WHO; 1998.

20. Malachias MVB, Póvoa RMS, Nogueira AR, Souza D, Costa LS, Magalhães ME. 7a Diretriz Brasileira de Hipertensão Arterial. Arq Bras Cardiol 2016; 107(3):183.

21. Baecke JA, Burema J, Frijters JE. A short questionnaire for the measurement of habitual physical activity in epidemiological studies. Am J Clin Nutr 1982; 36(5):936-942.

22. Florindo AA, Latorre DO. Validação e reprodutibilidade do questionário de Baecke de avaliação da atividade física habitual em homens adultos. Rev Bras Med Esporte 2003; 9(11):121-128.

23. Fernandes RA, Zanesco A. Early physical activity promotes lower prevalence of chronic diseases in adulthood. Hypertens Res 2010; 33(9):926-931.

24. Hertogh EM, Monninkhof EM, Schouten EG, Peeters PH, Schuit AJ. Validity of the Modified Baecke Questionnaire: Comparison with energy expenditure according to the doubly labeled water method. Int $J$ Behav Nutr Phys Act 2008; 5:30.

25. Perrier JF. Modulation of motoneuron activity by serotonin. Dan Med J 2016; 63(2):B5204.

26. Codogno JS, Fernandes RA, Monteiro HL. Physical activity and healthcare cost of type 2 diabetic patients seen at basic units of healthcare. Arq Bras Endocrinol Metabol 2012; 56(1):6-11.

27. Kang S, Xiang X. Physical activity and health services utilization and costs among U.S. adults. Prev Med 2017; 96:101-105.

28. Seegers V, Petit D, Falissard B, Vitaro F, Tremblay RE, Montplaisir J, Touchette E. Short Sleep Duration and Body Mass Index: A Prospective Longitudinal Study in Preadolescence. Am J Epidemiol 2011; 173(6):621629.
29. Silva GE, Goodwin JL, Parthasarathy S, Sherrill DL, Vana KD, Drescher AA, Quan SF. Longitudinal Association between Short Sleep, Body Weight, and Emotional and Learning Problems in Hispanic and Caucasian Children. Sleep 2011; 34(9):1197-1205.

30. Wells JC, Hallal PC, Reichert FF, Menezes AM, Araújo CL, Victora CG. Sleep Patterns and Television Viewing in Relation to Obesity and Blood Pressure: Evidence from an Adolescent Brazilian Birth Cohort. Int J Obes 32(7):1042-1049.

31. Bonke J. Trends in short and long sleep in Denmark from 1964 to 2009, and the associations with employment, SES (socioeconomic status) and BMI. Sleep Med 2015; 16(3):385-390.

32. Crispim CA, Zalcman I, Dáttilo M, Padilha HG, Tufik S, Mello MT. Relação entre sono e obesidade: uma revisão da literatura. Arq Bras Endocrinol Metab 2007; 51(7):1041-1049.

33. Tanik N, Sarp U, Ucar M, Celikbilek A, Balbaloglu O, Ak H, Atalay T, Arik HO, Okyay MY, Inan LE. Pain, depression and sleep disorders in patients with diabetic and nondiabetic carpal tunnel syndrome: a vicious cycle. Arquivos de Neuro-Psiquiatr 2016; 74(3):207-211.

34. Gonzaga NC, Sena ASS, Coura AS, Dantas FG, Oliveira RC, Medeiros CC. Sleep quality and metabolic syndrome in overweight or obese children and adolescents. Rev Nutr 2016; 29(3):377-389.

35. Anderson LH, Whitebird RR, Schultz J, McEvoy CE, Kreitzer MJ, Gross CR. Healthcare utilization and costs in persons with insomnia in a managed care population. Am J Manag Care 2014; 20(5):157-165.

Artigo apresentado em 05/07/2017

Aprovado em 17/04/2018

Versão final apresentada em 19/04/2018 